\title{
Diagnostic and therapeutic problems in two patients with antiphospholipid antibodies, heart valve lesions, and transient ischaemic attacks
}

\author{
R A ASHERSON, ${ }^{1}$ D G GIBSON,$^{2}$ D W EVANS ${ }^{3}$ E BAGULEY, ${ }^{1}$ AND \\ G R V HUGHES ${ }^{1}$
}

From the ${ }^{1}$ Lupus Arthritis Research Unit, The Rayne Institute, St Thomas's Hospital, London; the ${ }^{2}$ Department of Cardiology, Brompton Hospital, Fulham Road, London; and the ${ }^{3}$ Department of Cardiology, Papworth Hospital, Papworth Everard, Cambridge

SUMmaRY Two young women (aged 32 and 25 years) with systemic lupus erythematosus and heart valve lesions in association with antiphospholipid antibodies are presented. In addition to the presence of the 'lupus anticoagulant' and false positive Venereal Disease Research Laboratory (VDRL) tests, both patients had high levels of IgG anticardiolipin antibodies. The first patient additionally had contraceptive induced chorea, chorea gravidarum, seven miscarriages, livedo reticularis, pulmonary embolism, and thrombocytopenia and developed culture negative endocarditis as well as hypertension. The second patient, who had presented with hypertension, developed aortic and mitral regurgitation, suspected myocarditis, manifested transient ischaemic attacks, and responded well to anticoagulation and steroid treatment.

Key words: systemic lupus erythematosus.

The most frequently diagnosed cardiac lesion in systemic lupus erythematosus (SLE) is pericarditis, almost always symptomatic, whereas valve lesions, although often seen at necropsy are rarely symptomatic but may be diagnosed by Doppler echocardiography. ${ }^{1-4}$ Myocarditis is much less common. ${ }^{5}$

We present two patients who developed haemodynamically significant valve lesions and SLE; both possessed antiphospholipid antibodies in high titre. The presence of these antibodies provoked speculation as to their relation to the valve lesions and caused problems with treatment.

\section{Case reports}

PATIENT 1

This Caucasian woman of 19 years was well until 1973. Between November 1973 and October 1974, while taking the oral contraceptive, she had persistent involuntary movements of both hands and tongue. Chorea was diagnosed and contraceptive

Accepted for publication 22 March 1988.

Correspondence to Dr R A Asherson, Lupus Arthritis Research Unit, The Rayne Institute, St Thomas's Hospital, London SE1 7EH. treatment was stopped. There followed seven miscarriages, four of which were accompanied by 'chorea gravidarum', usually starting within two weeks of becoming pregnant and stopping spontaneously two or three weeks after the miscarriages. Repeated blood tests showed positive antinuclear antibodies (ANAs) in moderate titres on more than one occasion, and she was also found to have a false positive VDRL test. By 1982 she had developed an apical pansystolic murmur (grade 2/4) indicative of mitral regurgitation. A diagnosis of SLE was made on serological grounds. Two dimensional echocardiography performed in 1984 showed the mitral valve leaflets to be slightly thickened at their edges, with normal aortic tricuspid and pulmonary valves. There did not appear to be any vegetations present, and left ventricular function was good. The left atrium was marginally enlarged at $\mathbf{4 1} \mathrm{mm}$ (normal 19-40). She developed hypertension during early $1984(200 / 110 \mathrm{mmHg})$ and was treated with nifedipine SR $20 \mathrm{mg}$ twice daily in addition to NavidrexK. By this time she had noticed the development of livedo reticularis, particularly on her arms. In 1986 she had a chest infection for which she received antibiotic treatment but some months later still felt 
948 Asherson, Gibson, Evans, Baguley, Hughes

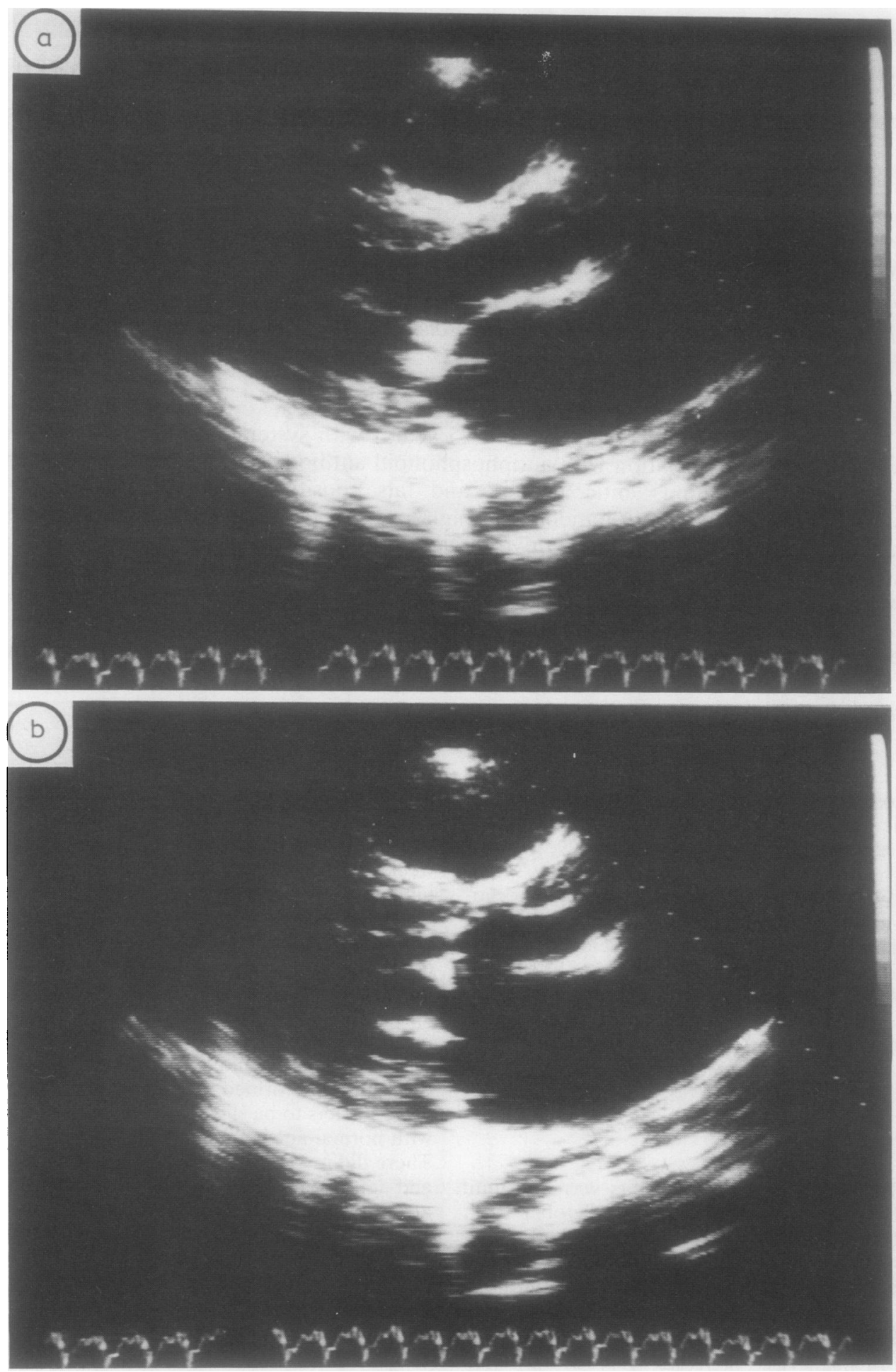

Fig. 1 Echocardiogram May 1986. Left parasternal long axis view in (a) systole and (b) diastole showing echo densities $\varrho$ consistent with vegetations on both leaflets of the mitral valve. 
unwell and was eventually admitted to hospital complaining of nausea, vomiting, and haemoptysis. On admission she was in congestive cardiac failure and was also anaemic with hepatomegaly and splenomegaly. She was treated with diuretics and transfused with four units of blood, but her condition appeared to worsen. She was transferred to the regional cardiac unit at Papworth Hospital. During this admission she developed severe left hypochondrial pain associated with an audible friction rub over the left anterior chest wall, indicative of pulmonary embolism, confirmed by ventilation/perfusion scan. She now had a platelet count of $48 \times 10^{9} / 1$, antiplatelet antibodies, and a prolonged prothrombin time of $70 \mathrm{~s}$ (control $37 \mathrm{~s}$ ). The ANA titre was positive at $1 / 100$, but DNA binding was normal. Immune complexes were raised $(64 \% v$ normal $0-24 \%$ ) as were anticardiolipin antibodies (59 GPL units $v$ normal $<5$ GPL units). Immunoglobulins were normal. Although blood cultures were repeatedly negative, urine microscopy showed 8-10 red blood cells per high power field and some hyaline casts. Chest $x$ ray showed cardiomegaly (transverse diameter $165 \mathrm{~mm}$ ) with some left midzone shadowing. Echocardiography (Figs $1 \mathrm{a}$ and $\mathrm{b}$ ) now showed sessile vegetations on both leaflets of the mitral valve. Culture negative, infective endocarditis was diagnosed, and she was given intravenous penicillin, gentamycin, and oral amoxycillin for two weeks. When discharged treatment was continued with nifedipine SR, twice daily, Frumil once a day, ferrous sulphate $200 \mathrm{mg}$ three times a day, and warfarin.

She remained generally unwell. After suffering from a respiratory infection she was readmitted in February 1987 with a suspected recurrence of bacterial endocarditis. There was now finger clubbing (Fig. 2) and periodontal pocketing around a molar tooth (later extracted) was evident. Her white blood cell count was $10.4 \times 10^{9} / 1$ and haemoglobin $101 \mathrm{~g} / \mathrm{l}$ with erythrocyte sedimentation rate raised to $98 \mathrm{~mm} / \mathrm{h}$. A single blood culture was positive for Staphylococcus albus. Because of the one positive culture, in the context of the haematological findings and her symptoms of malaisé, she was again treated for infective endocarditis. She was subsequently referred to St Thomas's Hospital for further evaluation. At this stage she was found to have the 'lupus anticoagulant', extremely high antibody titres to cardiolipin (120 GPL units, MPL units negative). Florid livedo reticularis had developed over both legs as well as on the arms. Her blood pressure was $130 / 95 \mathrm{mmHg}$ (during treatment with diuretics). She was treated with high dose steroids (prednisolone $60 \mathrm{mg}$ daily) and anticoagulated with warfarin, both of which were

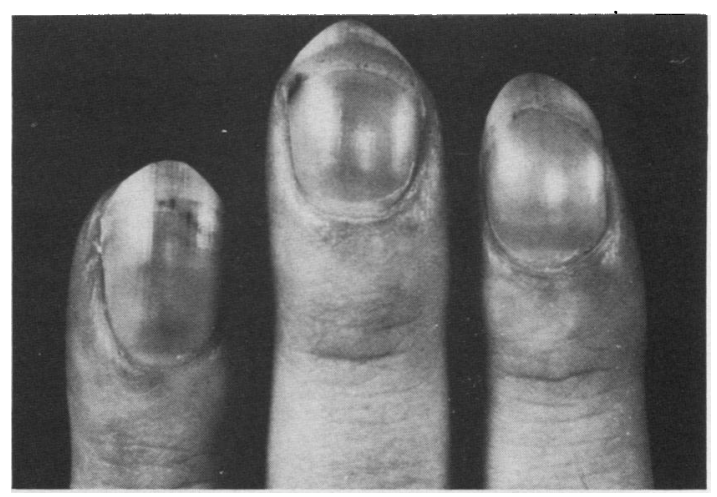

Fig. 2 Finger clubbing and splinter haemorrhages present in patient 1.

gradually reduced and discontinued over one year. The hypertension was controlled with nifedipine and frusemide. At one year follow up she complained of intermittent diplopia and is awaiting a computed tomographic scan for suspected transient ischaemic attacks (TIAs). Repeat echocardiograph showed extensive thickening of the mitral valve and some developing stenosis (Figs $3 a$ and b).

PATIENT 2

This 25 year old Caucasian woman developed hypertension in 1985 while taking the contraceptive pill. This settled spontaneously on withdrawal of the oral contraceptive without any specific treatment. Thereafter she remained well until five weeks before her admission to the Brompton Hospital in late 1986 when she developed lethargy, drowsiness, and exertional dyspnoea. There had been some weight loss and, additionally, she had developed a 'butterfly' rash on the malar area of the face, a distal petechial eruption with subungual haemorrhages, and a severe left hemicranial headache. This was followed by transient weakness of the right side of the body with some residual weakness of the right leg. There had been no past history of rheumatic fever. The patient smoked 60 cigarettes a day and drank 10 pints of beer a week.

On examination she appeared unwell with blood pressure of $180 / 100 \mathrm{mmHg}$. Her pulse rate was $88 / \mathrm{min}$, regular and collapsing in character. She had periungual and subungual splinter haemorrhages. Jugular venous pressure was raised, and murmurs consistent with mitral and aortic regurgitation were audible. The chest was clear clinically. The liver edge was palpable, but there was no splenomegaly. Central nervous system examination was normal. Chest $x$ ray demonstrated cardiomegaly with pulmonary venous congestion and the electrocardiogram showed sinus rhythm with left ventricular 
950 Asherson, Gibson, Evans, Baguley, Hughes
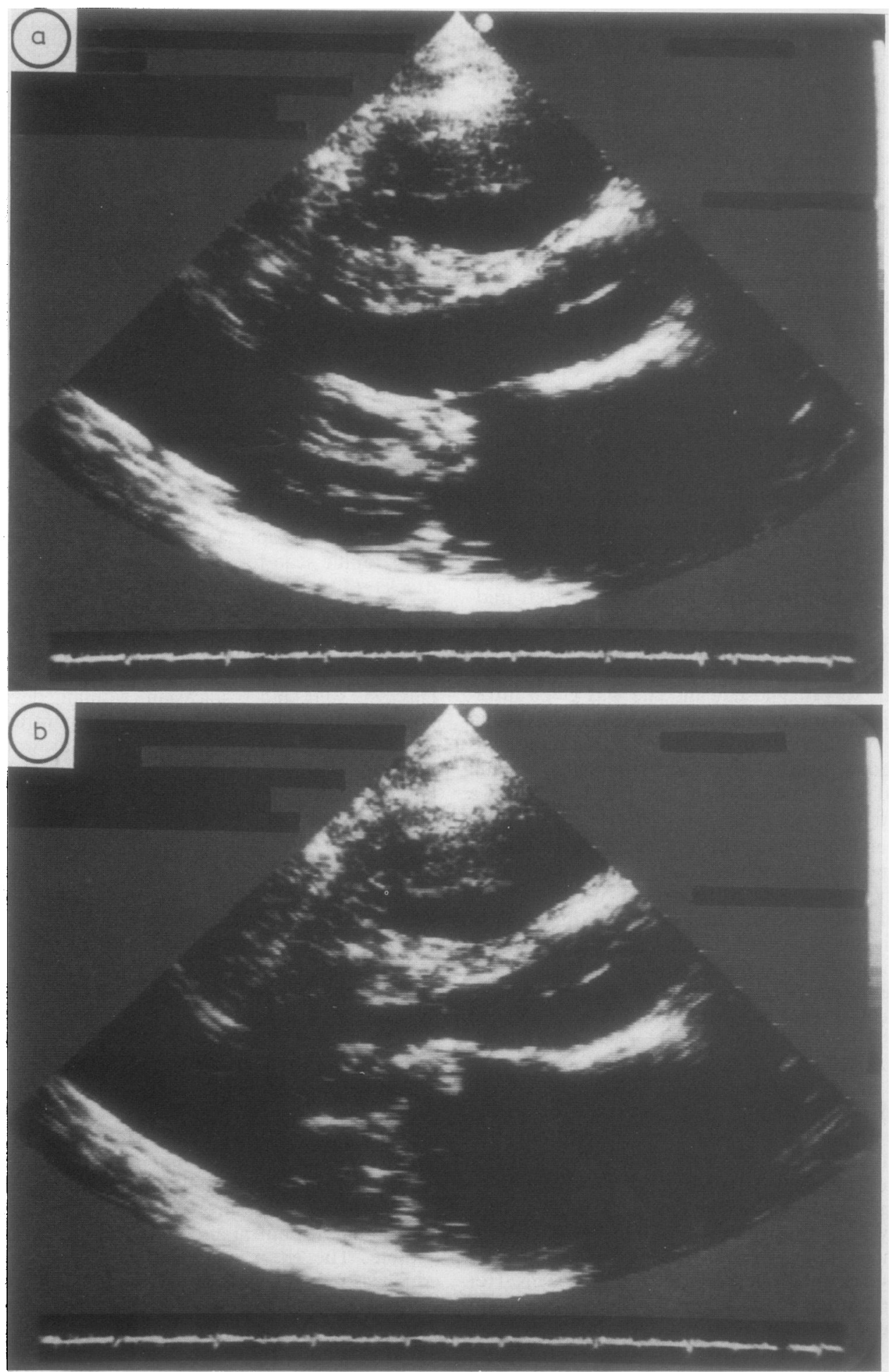
Fig. 3 Echocardiogram May 1987. Long axis view in (a) systole and (b) diastole showing thickening within the mitral $\underset{\varnothing}{\stackrel{Q}{Q}}$
valve and 'hooking' of the anterior cusp consistent with developing stenosis. 
hypertrophy on voltage criteria. Echocardiography did not show any evidence of vegetations. Aortic and mitral regurgitation was demonstrated by continuous wave Doppler (Fig. 4a). The left ventricular $M$ mode recording was very abnormal (Fig. 4b), with an increase in left ventricular cavity size to 6.9 $\mathrm{cm}$ at end diastole, falling to $5 \mathrm{~cm}$ at end systole. Although both septal and posterior wall thicknesses were increased at end diastole, systolic thickening was reduced. These findings were confirmed on the cross sectional record, and, in addition, myocardial echo amplitude recorded with standardised gain settings was significantly increased. The apexcardiogram showed major abnormalities during diastole compatible with considerable increase of left ventricular end diastolic pressure. These findings were compatible with myocardial oedema.

The white cell count was raised at $14.2 \times 10^{9} / \mathrm{l}$, with lymphopenia of $1.4 \times 10^{9} / 1$ (normal $1.5-3.5 \times$ $\left.10^{9}\right)$. Haemoglobin was $131 \mathrm{~g} / 1$ and platelet count $371 \times 10^{9} / \mathrm{l}$. The blood urea was raised at $10.8 \mu \mathrm{mol} / \mathrm{l}$ (normal 3.2-7.1) and serum creatinine was raised at $145 \mu \mathrm{mol} / 1$ (normal 44-88). Serum urate was also raised at $0.50 \mathrm{mmol} / \mathrm{l}$ (normal $0 \cdot 18-0 \cdot 39$ ). Clotting screen: prothrombin time $16 \cdot 4$, kaolin clotting time $56 / 30 \mathrm{~s}$, IgG immune complex binding positive. The DNA binding was negative, but the ANA titre was positive (1/160, speckled and diffuse pattern) and $C 4$ was reduced. Total proteins were $72 \mathrm{~g} / 1$ (normal 61-77). The rheumatoid arthritis latex, RoseWaaler, and Coombs' tests were negative. There was a circulating anticoagulant of the lupus type present and a high anticardiolipin antibody titre (79.6 GPL units, MPL units negative). The VDRL test was weakly positive (negative Treponema pallidum haemagglutination test). Blood cultures were repeatedly negative. At follow up three months later the white cell count had returned to normal levels, polyethylene glycol immune complexes were absent (31 mg IgG/1, normal 49). The crithidia DNA immunofluorescent test was repeatedly negative. Tests for antibodies to extractable nuclear antigens were also negative on a number of occasions.

Treatment was started with captopril for systolic hypertension, in addition to diuretics and prednisolone $20 \mathrm{mg}$ daily. Because of the right sided neurological disturbances she was also given Persantin and anticoagulant treatment (warfarin) was started. On this regimen she improved dramatically. The heart size returned to normal and the vasculitic type rash disappeared. Prednisolone was gradually reduced. The murmurs remain, and she is still hypertensive.

\section{Discussion}

Endocarditis in SLE, first described by Libman and
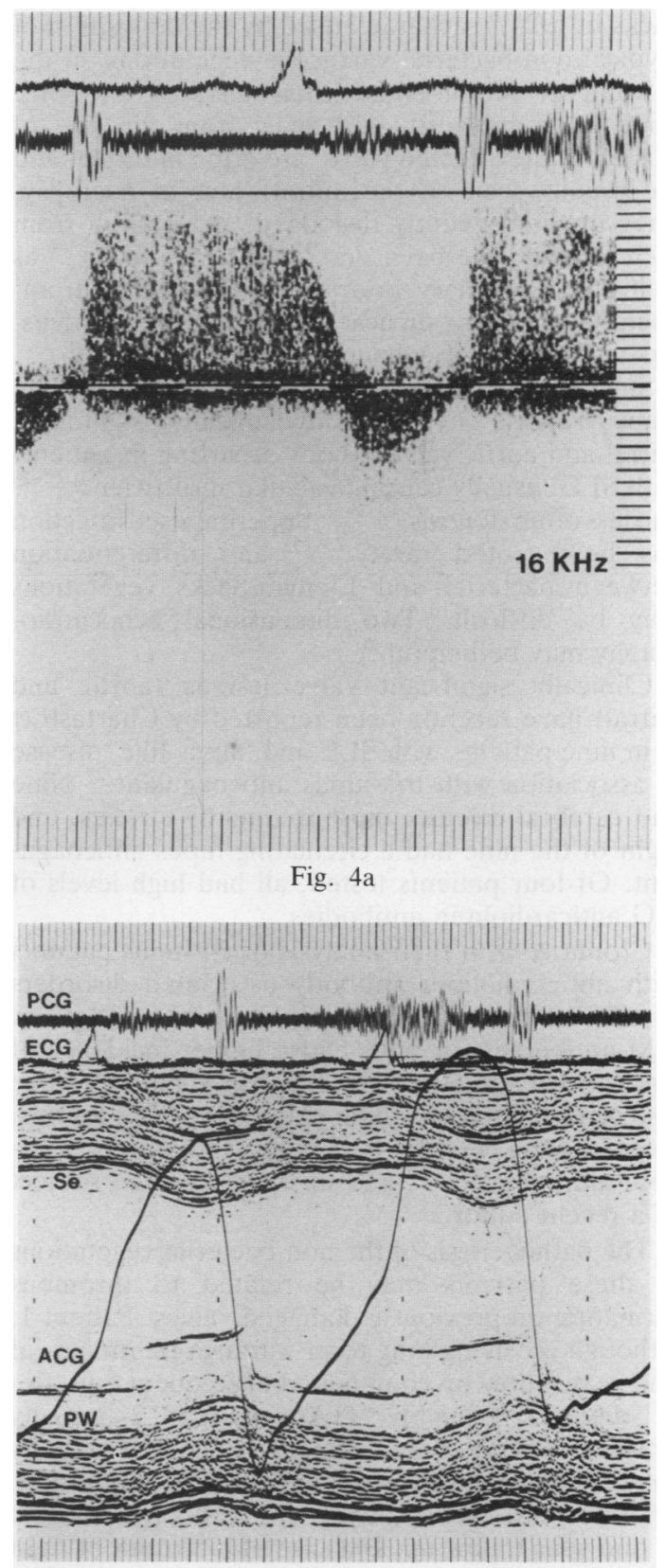

Fig. $4 \mathrm{~b}$

Fig. 4 (a) Continuous wave Doppler recording, showing aortic regurgitation. Simultaneous phono- and electrocardiograms have been recorded. Paper speed $10 \mathrm{~cm} / \mathrm{s}$. (b) Left ventricular $M$ mode echocardiogram with superimposed phono- (PCG), apex- (ACG), and electrocardiograms (ECG). Depth markers $=1 \mathrm{~cm}$, paper speed $10 \mathrm{~cm} / \mathrm{s}$. Se=septum; $P W=$ posterior wall of left ventricle. 
Sacks in $1924,{ }^{6}$ is characterised by the deposition of atypical non-bacterial verrucous vegetations on the valvular or mural endocardial surfaces, or both. They are usually situated away from the line of closure of the affected valve, are often multiple, and are usually seen on the mitral valve at necropsy. They are infrequently dislodged, but emboli from such lesions have been described to the brain ${ }^{7-9}$ as well as to coronary arteries. ${ }^{10}$ Pulmonary thromboembolism from verrucae originating on the tricuspid valve have also been recorded. ${ }^{\text {i1 }}$

Since the original descriptions there have been many reports of haemodynamically significant mitral and aortic valve lesions occurring in patients with SLE, usually causing valvular insufficiency ${ }^{12-20}$ and less often stenosis. ${ }^{10}{ }^{21}{ }^{22}$ Superimposed infection has been noted rarely, ${ }^{23-25}$ and differentiation between bacterial and Libman-Sacks vegetations may be difficult. Two dimensional echocardiography may be helpful. ${ }^{26}$

Clinically significant valve lesions (aortic and mitral) have recently been reported by Chartash $e t$ $a l$ in nine patients with SLE and 'lupus-like' disease in association with the lupus anticoagulant. ${ }^{27}$ Nine had cerebral disease, most frequently strokes, and eight of the nine had a circulating lupus anticoagulant. Of four patients tested, all had high levels of IgG anticardiolipin antibodies.

Cronin et al in their analysis of 64 lupus patients with anticardiolipin antibody associated disorders found that their patients with high titres of IgG or IgM antibodies, or both had a higher incidence of endocardial disease. ${ }^{28}$ Several other authors have also reported patients with coincident valve lesions, 'vegetations', cerebral ischaemia, and antiphospholipid antibodies, ${ }^{29-31 a}$ and this has been the subject of a recent editorial. ${ }^{32}$

The pathogenesis of the non-bacterial vegetations in these patients may be related to thrombus formation on previously damaged valves. Patient 1 , although receiving long term warfarin treatment, at one year follow up complained of frequent episodes of diplopia, possibly TIAs. Patient 2 initially presented with hypertension. Echocardiography showed she had both mitral and aortic regurgitation. The murmurs were still present with cardiomegaly at one year follow up. Because of intermittent right sided hemisensory disturbances (TIAs) treatment was started with anticoagulants and antiplatelets (warfarin and Persantin) and one year later, though still hypertensive, she had no further recurrence of the TIAs.

Both these patients had several of the manifestations associated with the 'antiphospholipid syndrome'. 33 The association of antiphospholipid antibodies with chorea, occurring after administra- tion of oral contraceptives or during pregancy, has been noted previously. ${ }^{35-37}$ The valve lesions in $\overrightarrow{\vec{F}}$ patient 1 were accompanied by finger clubbing and $\stackrel{?}{?}$ subungual splinter haemorrhages. Evidence of $\frac{}{2}$ bacterial endocarditis was not convincing, though $\frac{\overline{0}}{\bar{N}}$ she was treated on two occasions for culture $\frac{\Phi}{\sigma}$ negative endocarditis. Patient 2 did not have any 2 vegetations demonstrable by echocardiography, but $\%$ had thickened valve margins, suggestive of $\vec{\circ}$ a valvulitis.

A recent case report recorded a young woman $\overrightarrow{\vec{\omega}}$ with positive anticardiolipin antibodies who not only demonstrated endocardial 'nodules' but also $\frac{\overline{2}}{2}$ occlusion of many intramyocardial arteries with $\stackrel{t}{-}$ thrombus unaccompanied by vasculitis. ${ }^{38}$ The patient succumbed from circulatory failure. It is $\overrightarrow{0}$ possible that our patient 2 suffered from a similar process, producing an echocardiographic impression of 'myocarditis' or 'pseudocardiomyopathy'.

The relation between the valve lesions and the $\vec{z}$ presence of the antiphospholipid antibodies in these patients remains speculative. It is likely that the $\mathbb{S}$ underlying disease process itself was responsible for뭉 their development. The importance of anticoagulation in addition to standard treatment to preveg $\vec{t} \overrightarrow{0}$ possible thromboembolic complications, partict-ळ larly cerebral, is emphasised, however, and shoufd be considered in any lupus patient with valve lesions? in the presence of these antibodies.

\section{References}

1 Heijtmancik M, Wright J C, Ouint R, Jennings F L. The $\overline{\bar{O}}$ cardiovascular manifestations of systemic lupus erythematosus. Am Heart J 1964; 68: 118-30.

2 Yurchak P, Levine S, Gaulling R. Constrictive pericarditis complicating systemic lupus erythematosus. Circulation 1965 31: 113-8.

3 Bergen S. Pericardial effusion as manifestation of systemic lupus erythematosus. Circulation 1960; 22: 144-50.

4 Estes D, Christian C L. The natural history of systemic lupus erythematosus by prospective analysis. Medicine (Baltimore) $\varrho$ 1971; 50: 85-95.

5 Borenstein D G, Fye B, Arnett F C, Stevens M B. Myocarditis of systemic lupus erythematosus. Association with myositis. Ann Intern Med 1978; 89: 619-24.

6 Libman E, Sacks B. A hitherto undescribed form of valvularo and mitral endocarditis. Arch Intern Med 1934; 33: 701-37.

7 Fox I C, Spence A M, Whealis R F, Healey L A. Cerebral embolism in Libman-Sacks endocarditis. Neurology 1980; 30:" 487-91.

8 Gorelick P B, Rusinowitz M S, Tiku M, McDonald L W, N Robbins L. Embolic stroke complicating systemic lupus erythematosus. Arch Neurol 1985; 42: 813-5.

9 Von Albertini. Atypische verrucosa endocarditis Libman-Sackso vera beziehungnzum lupus erythematodes. Actis Cardiology 1947; 12: 133-69.

10 Lerman B B, Thomas L C, Abrahams G D, Pitt B. Aortic stenosis associated with systemic lupus erythematosus. $A m$ J Med 1982; 72: 707-10.

11 Yamabe H, Kikuchi K, Sugawara N, et al. Systemic lupus erythematosus complicated with pulmonary thromboembolism $\vec{D}$ 
originating from the verrucac of Libman-Sacks endocarditis. Japanese Journal of Nephrology 1984; 26: 323-31.

12 Myerowitz P D, Michaelis L L, Mclntosh C L. Mitral valve replacement for mitral regurgitation due to Libman-Sacks endocarditis. Report of a case. J Thorac Cardiovasc Surg 1974: 67: 869-74.

13 Bulkley B H, Roberts W C. Systemic lupus erythematosus as a cause of severe mitral regurgitation: new problems in an old disease. Am J Cardiol 1975; 35: 305-8.

14 Murray F T, Fuleihan D S. Cornwall C S, Pinals R S. Acute mitral regurgitation from ruptured chordae tendineae in systemic lupus erythematosus. J Rheumatol 1975; 2: 454-9.

15 Paget S A, Bulkley B H, Grauer L E, Seningen R. Mitral valve disease in systemic lupus erythematosus-a cause of severe congestive heart failure reversed by valve replacement. Am J Med 1975; 59: 134-9.

16 Shapiro R F, Gambol C N, Wiesner K B, et al. Immunopathogenesis of Libman-Sacks endocarditis. Assessment by light and immunofluorescent microscopy in two patients. Ann Rheum Dis 1977; 36: 508-16.

17 Shulman H J, Christian C L. Aortic insufficiency in systemic lupus erythematosus. Arthritis Rheum 1969: 12: 138-46.

18 Bernhard G C, Lange R L, Hensley G T. Aortic disease with valvular insufficiency as the principal manifestation of systemic lupus erythematosus. Ann Intern Med 1969; 71: 81-7.

$19 \mathrm{Oh}$ W M, Taylor R T, Olssen E J. Aortic regurgitation in systemic lupus erythematosus requiring aortic valve replacement. Br Heart $J$ 1974; 36: 413-6.

20 Thandroyen F T, Matisonn R E, Weire K. Severe aortic incompetence caused by systemic lupus erythematosus. $S A f r$ Med J 1978; 54: 166-8.

21 Vaughton K C. Walker D R, Sturridge M F. Mitral valve replacement for mitral stenosis caused by Libman-Sacks endocarditis. Br Heart J 1979; 41: 730-3.

22 Pritzker M R. Ernst J D, Caudill C, Wilson S D. Weaver W F, Edwards $\mathrm{J}$ E. Acquired aortic stenosis in systemic lupus erythematosus. Ann Intern Med 1980; 93: 434-6.

23 Bomalaski J, Talano J V. Perlomon S. New heart murmur and fever in a patient with systemic lupus erythematosus. Arch Intern Med 1982; 142: 823-4.

24 Waisman G, Catoggio L J, Fongi E G. Belzitic C, Precerutti J A. Systemic lupus erythematosus and endocarditis. Clin Exp Rheumatol 1986; 4: 292-4.

25 Lehman J J A, Palmeri S T, Hastings C, Klippel J H, Plotz P H. Bacterial endocarditis complicating systemic lupus erythematosus. J Rheumatol 1983; 10: 655-8.
26 Kahn A, Amor B, de Vernejoul F, Saportal L. Libman-Sacks endocarditis: the diagnostic importance of two dimensional echocardiography. Br J Rheumatol 1985; 24: 187-90.

27 Chartash E K, Paget S A, Lockshin M D. Lupus anticoagulant associated with aortic and mitral valve insufficiency. Arthritis Rheum 1986; 29 (suppl): S95.

28 Cronin M E. Biswas R, Van Der Straeton C. Fleisher T A. Klippel J H. IgG and IgM anticardiolipin antibodies (ACA) in patients with lupus with ACA associated clinical syndromes. J Rheumatol 1988; 15: 795-8.

29 D'Alton J G, Preston D M, Bormanis J. Multiple transient ischaemic attacks, lupus anticoagulant and verrucous endocarditis. Stroke 1983; 16: 512-4.

30 Anderson D, Bell D, Lodge R, et al. Recurrent cerebral ischaemia and mitral valve vegetation in a patient with lupus anticoagulant. $J$ Rheumatol 1987; 14: 839-42.

31 Tsokos G C. Tsokos M, Le Rietre N G H, Klippel J H. A clinical and pathological study of cardiovascular disease in patients with systemic lupus erythematosus. Semin Arthritis Rheum 1986; 16: 70-8.

31a Ford PH, Ford SE, Lillicrap DP. Association of lupus anticoagulant with severe valvular heart disease in SLE.J Rheumatol 1988; 15: 597-600.

32 Asherson R A. Lubbe W F. Cerebral and valve lesions in systemic lupus erythematosus. Association with antiphospholipid antibodies? J Rheumatol 1988; 15: 539-43.

33 Asherson R A. Harris E N. Anticardiolipin antibodies-clinical associations. Postgrad Med J 1986; 62: 1081-7.

34 Harris E N, Asherson R A. Hughes G R V. Antiphospholipid antibodies-autoantibodies with a difference. Ann Rev Med 1988; 39: 261-71.

35 Asherson R A, Harris E N, Gharavi A E, Hughes G R V. Systemic lupus erythematosus, anti-phospholipid antibodies, chorea and oral contraceptives. Arthritis Rheum 1986; 29: 1535-6.

36 Asherson R A. Harris E N. Hughes G R V, Farquharson R G. Complications of oral contraceptives and anti-phospholipid antibodies. Arthritis Rheum 1988: 31: 575-6.

37 Lubbe W F, Walker E P. Chorea gravidarum associated with circulating lupus anticoagulant. Successful outcome of pregnancy with prednisolone and aspirin therapy. $\mathrm{Br} J$ Obstet Gynaecol 1963; 90: 487-90.

38 Brown J H. Doherty C C. Allen D C, Morton P. Fatal cardiac failure due to myocardial microthrombi in systemic lupus erythematosus. $\mathrm{Br}$ Med J 1988; 296: 1505. 